\title{
Modelling farm production decisions under an expenditure constraint
}

\section{Journal Article}

\section{Author(s):}

Kumbhakar, Subal C.; Bokusheva, Raushan

Publication date:

2009-09

Permanent link:

https://doi.org/10.3929/ethz-b-000413528

\section{Rights / license:}

In Copyright - Non-Commercial Use Permitted

\section{Originally published in:}

European Review of Agricultural Economics 36(3), https://doi.org/10.1093/erae/jbp031 


\title{
Modelling farm production decisions under an expenditure constraint
}

\author{
Subal C. Kumbhakar \\ State University of New York, Binghamton, USA
}

\section{Raushan Bokusheva}

ETH Zurich (Swiss Federal Institute of Technology), Switzerland

Received March 2008; final version received May 2009*

\begin{abstract}
We use the indirect production function approach in the stochastic frontier framework to estimate separately the output losses due to the presence of a budget constraint and technical inefficiency. We develop a methodology for estimating the severity and testing the significance of the expenditure constraint at individual producer level. Our results, based on the farm data from three Russian regions from 1999 to 2003, show that the majority of the farms studied were expenditure-constrained during the study period. Expenditure constraints caused, on average, a potential output loss of 20 per cent. Output loss due to technical inefficiency, on average, is found to be around 13 per cent.
\end{abstract}

Keywords: indirect production function, expenditure constraint, stochastic frontier, technical efficiency, Russian agriculture

JEL classification: Q13, D24

\section{Introduction}

Input use decisions and the productive efficiency of Russian farms have been the subject of many investigations in the past decade (Sotnikov, 1998; Sedik et al., 1999; Osborne and Trueblood, 2002; Arnade and Trueblood, 2002; Bezlepkina et al., 2005). These studies primarily sought to evaluate the effect of economic transition on the allocation of productive resources. In the context of Russia's centrally planned economy, farm production inputs were delivered according to the government's plans and thus were not necessarily under the control of farmers' decision-making. Producers' input allocation decisions have become more important in the transition context, primarily because of the need for increased efficiency in input use. At the same time, low farm liquidity and limited access to external finance due to financial market imperfections have seriously constrained producers' input decisions during transition. We hypothesise that limited budgets for the 
purchase of variable inputs may have induced sub-optimal usage of farm inputs, resulting in losses in productivity and efficiency.

Lee and Chambers (1986) showed that if expenditure constraints are present and binding, then profit-maximisation cannot be regarded as an adequate representation of producers' behaviour. In fact, a profit-maximising assumption presupposes that farms face no constraints in their input allocation decisions. On the other hand, in the cost-minimising formulation, farmers are assumed to minimise the cost of a pre-determined level of output. Although this formulation incorporates a constraint on producers' behaviour, the exact nature of the constraint seems to be mis-specified, since the constraint is expressed in terms of output rather than cost outlay (Ferguson, 1969; Chambers, 1982).

Arnade and Gopinath (2000) analysed the effects of expenditure constraints on Russian farmers' output at the regional level. With the use of data envelopment analysis (DEA), they found expenditure constraints to be present in 54 of the 73 agricultural regions for the years 1994 and 1995. The study also estimated profit loss due to financial constraints. Their estimate of financial efficiency, assessed as the ratio of constrained to unconstrained profit, is unexpectedly high. This might be caused by the use of aggregate data, which could have masked the severity of expenditure constraints operating at the micro level.

Recently, Bezlepkina et al. (2005) studied the effect of additional finance in the form of state subsidies and found that government subsidies had a positive effect on dairy farm profits in the Moscow region during the period 1995 to 2001. ${ }^{1}$ This study employed an indirect (dual) technology representation and regarded subsidies as an additional regressor in the profit function. However, the analysis by Bezlepkina et al. (2005) did not consider the effect of constraints on either farm profit or output. In addition, though this analysis revealed that subsidies relieved credit constraints of dairy farms in the Moscow region during the period 1996-2001, empirical evidence suggests a significant reduction in the extent of government subsidies in Russian agriculture. In fact, the share of subsidies in total agricultural production value shrank from 15 per cent in 1992 to 3-5 per cent after 1998 (Table A1 in Appendix A). ${ }^{2}$ Moreover, in contrast to the earlier years of transition, Russian farms have not more recently been able to benefit from soft budget constraints (SBCs). After 1998, the Russian government strengthened financial discipline and forced farms to repay their debts to federal budgetary and non-budgetary funds (Government of Russia, 2001). ${ }^{3}$ Finally, since 2001

1 These authors, however, provided empirical evidence of decreasing government support during transition and particularly after the 1998 financial crisis. According to their assessments, the share of subsidies in farm revenue was 2.4 per cent in 2000 (Bezlepkina et al., 2005). Considering this low level of state support after 1998, government subsidies have hardly relieved Russian farms' budget constraints in recent years.

2 Taking into account high inflation rates during transition and the fact that subsidies are granted to farms primarily a posteriori in Russia, the share of subsidies in real terms would have been even lower.

3 Bezlepkina et al. (2005) estimated that for farms in the Moscow region, the share of subsidies in farm revenue declined from 12.5 per cent in 1997-98 to 2.4 per cent in 2000. According to 
farm solvency has been an important condition for participating in government subsidy programmes (Bokusheva et al., 2009).

Furthermore, several empirical studies have been conducted to analyse the effect of financial constraints on farms' investment behaviour in transition (Latruffe, 2005; Bokusheva et al., 2009). Their results show that financial constraints do indeed affect farm investment. However, the rationale of these studies is limited to testing the sensitivity of farm investment to external finance as evidence of imperfections in rural financial markets.

The financial crisis of 1998 provoked a considerable increase in demand for domestic products that positively affected the terms of trade facing Russian agriculture. The empirical evidence shows that since 1999 Russian farms have been experiencing increasing returns to scale (Bokusheva and Hockmann, 2006). At the same time, due to budget constraints, Russian farms were seriously limited in their use of variable inputs, which restrained them from exploiting the benefits of economies of scale through the use of more variable inputs. Because of this, we suggest that output maximisation might more adequately describe Russian farmers' behaviour than cost minimisation or an unconstrained profit maximisation.

In this study, we extend the approach developed by Lee and Chambers (1986), who showed that the profit-maximising output supply under expenditure constraints is equal to the revenue-maximising supply evaluated at optimal input levels. Lee and Chambers derived a methodology that can be used to test whether expenditure constraints are binding for the entire sample of farms. In this paper, we consider an extension of their approach that can determine the level of expenditure constraints for individual producers as well as their output losses caused by the presence of expenditure constraints.

Since expenditure-constrained profit maximisation is equivalent to output maximisation subject to expenditure constraint, we apply the indirect production function (IPF) approach. ${ }^{4}$ The IPF is based on output maximisation subject to a given technology, a set of quasi-fixed inputs and a given budget for the purchase of variable inputs. Apart from being an appropriate characterisation of producer behaviour in the presence of financial constraints, the IPF approach has the advantage of allowing the direct computation of the effect of a budget constraint on output produced.

In addition to facing a budget constraint, a farm may be technically inefficient. That is, it might not be able to operate on the production frontier given

Bezlepkina (2004), about 65 per cent of dairy farms in the sample from the Moscow region were classified as operating under SBCs from 1996 to 1998, whereas in 1999 this share dropped to 10 per cent.

4 The rationale behind the IPF is similar to cost minimisation. In both optimisation problems, the marginal rate of substitution is equated to the ratio of factor prices (Chambers, 1982). However, while the IPF determines output as the solution of the optimisation problem, in the costminimisation framework the output is treated as predetermined and the solution determines the minimum cost. 
its input quantities. We use stochastic frontier analysis (SFA) to model technical inefficiency. This enables us to separate output losses due to expenditure constraints from those due to technical inefficiency. Moreover, we are interested in identifying factors that might have influenced both the extent to which individual farms experienced budget constraints and the farm's technical efficiency. This part of the analysis may be relevant for deriving policy implications from the research.

Accordingly, the objectives of this paper are: (i) to represent the expenditure-constrained technology by specifying a flexible functional form of the IPF; (ii) to develop methodology for estimating the severity and testing the significance of an expenditure constraint for an individual producer; (iii) to incorporate technical inefficiency into the IPF model to disentangle two independent sources of output loss, namely an expenditure constraint and technical inefficiency; and (iv) estimate the IPF using a system approach.

Our empirical analysis uses survey data for 90 farms from three different regions in Central, South and Volga Russia from 1999 to 2003. The data contain results of structured interviews with farm managers conducted in 2004, as well as farm accounting data from 1999 to 2003. In this paper, we utilise farm bookkeeping data and data on basic characteristics of the farm, enterprise organisation, managerial characteristics, production-related characteristics, and the farm's business environment.

The paper is organised as follows. The next section presents the general concept of the IPF, both with and without technical inefficiency. Section 3 discusses the estimation procedure employed. The data are described in Section 4. Estimation results are presented and discussed in Section 5. A summary of the main findings is reported in the concluding section.

\section{Model}

\subsection{The IPF}

The IPF is an appropriate tool to use when the objective is to maximise output subject to a given technology, a set of quasi-fixed inputs and a given budget for the purchase of variable inputs. Underlying the IPF is the familiar formulation of a production function that relates inputs to output:

$$
y=f(\mathbf{x} ; \mathbf{z}),
$$

where $y$ is the output, $\mathbf{x}$ denotes a vector of $N$ variable inputs and $z$ denotes the quasi-fixed input vector of order $M$, and $f(\mathbf{x} ; \mathbf{z})$ is a non-decreasing, twice continuously differentiable and quasi-concave function of $\mathbf{x}$ and $\mathbf{z}$.

The budget constraint faced by the producer can be written as

$$
C=\mathbf{w}^{\prime} \mathbf{x},
$$

where $\mathbf{w}$ denotes the vector of variable input prices and $C$ represents the budget available to the producer for the purchase of variable inputs. 
If the producers maximise output, subject to the constraints in equations (1) and (2), the Lagrangean for the problem is

$$
L=f(\cdot)+\lambda\left(C-\mathbf{w}^{\prime} \mathbf{x}\right),
$$

where $\lambda$ denotes the Lagrange multiplier associated with the constraint in equation (2), and the choice variables are the inputs, $\mathbf{x}$. The exogenous variables are the elements in vectors $\mathbf{z}, \mathbf{w}$ and the total budget of the producer, $C$, while the input vector $\mathbf{x}$ and $\lambda$ are determined endogenously. Solving the first-order conditions $\left(f_{j}=\lambda w_{j}, \forall j\right.$ and $\left.C-\mathbf{w}^{\prime} \mathbf{x}=0\right)$, we get the solution for the endogenous variables in terms of the exogenous variables, that is,

$$
x_{j}^{*}=g_{j}(\mathbf{w} ; C ; \mathbf{z}), \forall j=1, \ldots, N,
$$

and

$$
\lambda^{*}=h(\mathbf{w} ; C ; \mathbf{z})
$$

Substituting the optimal values of $x_{j}^{*}(\dot{\mathrm{c}})$ from equation (4a) into equation (1) we get the optimal value of output:

$$
y^{*}=\psi(\mathbf{w} ; C ; \mathbf{z}) .
$$

Equation (5) represents the IPF, which expresses the maximum attainable output for the producer in a specified period as a function of the availability of funds, the price of variable inputs and the quantity of fixed inputs.

Unfortunately, the preceding analysis does not provide a framework within which we can determine which farms are expenditure-constrained, and what is the potential output loss due to the presence of budget constraints. To remedy this, we assume that the desired budget for a particular farm is $C^{*}$, which by definition cannot be lower than the actual expenditure $(C)$. That is, $C^{*} \geq C$, where the strict inequality means that the farm in question is expenditure constrained. The presence of this constraint means that the farm in question can only spend $C$ and not $C^{*}$, and because $C^{*} \geq C$, output will be lower, as will be profit. That is, output associated with $C^{*}\left(\right.$ i.e. $\left.y^{*}=\psi\left(\mathbf{w}, C^{*} ; \mathbf{z}\right)\right)$ will be higher than output associated with the budget $C$ (given in equation (5)).

Without loss of generality, we show this graphically in Figure 1 for a single input and single output. In this graph, the expression for profit $(\pi=p y-w x)$ is rewritten (in terms of output) as $y=(\pi / p)+(w / p) x$, where $p$ is output price. Thus, the vertical intercept of the line $y=(\pi / p)+(w / p) x$ measures (normalised) profit, $\pi / p$. Normalised profit without constraint is measured by the intercept of the solid line $\left(\pi^{A}\right)$ and profit associated with expenditure constraint is measured by the intercept of the dotted line $\left(\pi^{B}\right)$. It is clear from the figure that $\pi^{A}>\pi^{B}$, that is, profit is reduced due to the presence of expenditure constraints, ceteris paribus.

The optimisation problem with budget constraint involves maximising equation (1) subject to $C^{*} \geq C \Rightarrow C^{*} e^{-\eta}=C=\mathbf{w}^{\prime} \mathbf{x}, \quad \eta \geq 0$, where the available budget $C$ is expressed as the product of $C^{*}$ and the exponential of 


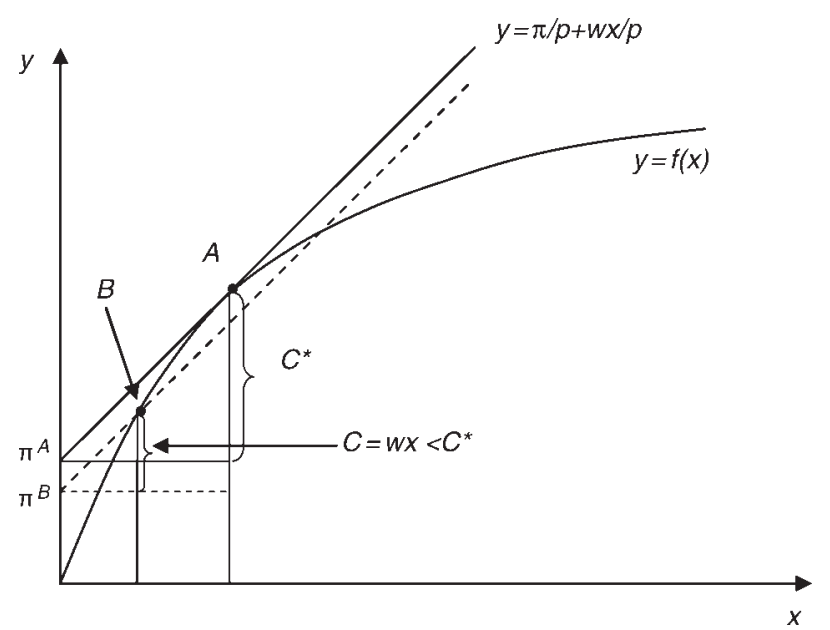

Figure 1. Output and profit with and without expenditure constraints.

Source: Authors' representation.

a non-positive random variable $(-\eta \leq 0)^{5}$. Then, the Lagrangean of the problem is

$$
L=f(\cdot)+\lambda\left(C^{*} e^{-\eta}-\mathbf{w}^{\prime} \mathbf{x}\right)=f(\cdot)+\lambda(C-\mathbf{w} / \mathbf{x}),
$$

which is not different from the Lagrangean shown in equation (3). Thus, the IPF is exactly the same. However, since we do not observe $C^{*}$, the corresponding output level $y^{*}$ cannot be observed. In other words, one can neither directly observe which producer is expenditure constrained nor the extent of such constraints from the IPF.

However, it is possible to get the necessary information and this is the main contribution of this paper. The information about the expenditure constraint (for each farm) can be obtained from the Lagrange multiplier $\lambda$. At the optimum, $\lambda=\partial L / \partial C=\partial y / \partial C{ }^{6}$ Then, one can obtain an estimate of $\lambda$ by differentiating the estimated IPF with respect to the observed expenditure $C$. If a farm is not expenditure constrained, its output will be the same as the profitmaximising level and the value of $\lambda$ will be one, especially when output is measured in value terms. That is, at the optimum, the return from spending an additional euro has to be matched by a return of one euro in additional revenue. If not, its profit can be increased by spending more (less) and the farm is not operating at the optimum. If the farm is subject to an expenditure constraint (i.e. $C^{*} \geq C$ ), the value of $\lambda$ will exceed one. This follows from the

5 We converted the inequality to an equality by introducing the non-negative random variable $\eta$, which is farm-specific (drawn from a distribution that ensures non-negativity). The value of $\eta$ indicates the degree (severity) of the expenditure constraint.

6 In this problem, $\lambda$ is the inverse of the marginal cost, i.e. $1 / \lambda=\partial C / \partial y$. The first-order condition requires that $\partial C / \partial y=p$ and since output is measured as farm revenue in our analysis, we normalise $p=1$. Thus, at the optimum, $1 / \lambda=\partial C / \partial y=1$, which shows that the optimal output level from the IPF is identical with the one from the unconstrained profit maximisation problem. 
assumption that the production function is concave in $\mathbf{x}$. Since we can estimate $\lambda$ for each farm (once the IPF is estimated), we can easily find out which farms are expenditure constrained.

Since at the optimum the value of $\lambda$ for an unconstrained farm is 1 , we can obtain $C^{*}$ as a solution of $C$ from the equation: $\partial y / \partial C=1$. The budget $C^{*}$ can then be plugged into the IPF to get the optimum (unconstrained) output level, $y^{*}$. The deviation of actual (predicted) output from the optimal output can then be viewed as output loss due to expenditure constraint. One can examine the extent (severity) of the expenditure constraint either in terms of cost or output. In the former case, we compare $C^{*}$ with $C$ and the difference for each farm indicates the extent of the expenditure constraint. In the latter case, one compares $y^{*}$ with $y$ and the difference for each farm measures the extent to which output is reduced due to the budget constraint. Since both $C^{*}$ and $y^{*}$ are functions of estimated parameters and data, one can compute confidence intervals for $C^{*}$ and $y^{*}$ to check whether the confidence interval includes the observed values. This can be done for each farm. Finally, we can also test the hypothesis that a particular farm is expenditure constrained. That is, the null hypothesis of interest is $H_{0}: \lambda=\partial y / \partial C=1$, which can be tested against the alternative hypothesis $H_{A}: \lambda>1$.

\subsection{The IPF with technical inefficiency}

We have thus far assumed that all farms are technically efficient. That is, given the inputs, the output produced is at its maximum from the technological point of view. If farms fail to produce the technically maximum level of output, the production function can be expressed as

$$
y=f(\mathbf{x} ; \mathbf{z}) e^{-u} \geq 0,
$$

where $u$ is a measure of technical inefficiency. Alternatively, $e^{-u} \leq 1$ is defined as technical efficiency. We can interpret $\left(1-e^{-u} \times 100\right.$ as the percentage loss of output for being technically inefficient.

Since technical inefficiency in equation (7) is neutral, it does not affect the marginal rate of technical substitution (the ratio of marginal product of inputs) between two inputs. Thus, input allocation is not affected by the presence of technical inefficiency. In other words, the solution for $x_{j}$ in equation (4a) is not affected by the presence of technical inefficiency. ${ }^{7}$ However, the solution for $\lambda$ and $y$ will be affected, in the following fashion:

$$
\begin{aligned}
& \lambda_{1}^{*}=\lambda^{*} e^{-u}=e^{-u} h(\mathbf{w} ; C ; \mathbf{z}) \\
& y_{1}^{*}=y^{*} e^{-u}=e^{-u} \psi(\mathbf{w} ; C ; \mathbf{z}) .
\end{aligned}
$$

This is quite straightforward to demonstrate. If we write the Lagrangean for

7 Here, we implicitly assume that farms are allocatively efficient. 
the present problem as

$$
L_{1}=f(\cdot) e^{-u}+\lambda_{1}\left(C-\mathbf{w}^{\prime} \mathbf{x}\right),
$$

the first-order conditions are: $f_{j} / f_{1}=w_{j} / w_{1}, \forall j=2, \ldots, N$, and $C-\mathbf{w}^{\prime} \mathbf{x}=0$. Thus, the solutions for $x_{j}$ in this problem are not different from those of the original problem without technical inefficiency. Since $y=f(\mathbf{x} ; \mathbf{z}) e^{-u}$, the IPF takes the form of equation (9). Furthermore, since $f_{j}(-)=\lambda w_{j}$, the solution of $\lambda$ from the original problem can be expressed as $\lambda^{*}=\sum_{j} f_{j}(\cdot) x_{j} / \sum_{j} w_{j}$ $x+=h(\mathbf{w} ; C ; \mathbf{z})$. In the present case with technical inefficiency $f_{j}(\cdot)=$ $\lambda w_{j} e^{-u}$, the solution for $\lambda_{1}$ is therefore $\lambda_{1}^{*}=e^{-u} \sum_{j} f_{j}(\cdot) x_{j} / \sum_{j} w_{j} x_{j}=$ $e^{-u} \lambda^{*}=e^{-u} h(\mathbf{w} ; C ; \mathbf{z})$, which gives equation (8). Since $e^{-u} \leq 1$, the marginal return to the euro $\left(\partial y / \partial C=\lambda_{1}\right)$ is lower. More specifically, the return is only 90 per cent if technical efficiency $\left(e^{-u}\right)$ is 0.9 .

To find out which farms are expenditure-constrained and by how much (or the affect it has on output), as well as the impact of inefficiency on output, we need to estimate $\lambda_{1}^{*}=e^{-u} h(\mathbf{w} ; C ; \mathbf{z})$ in which the $e^{-u} \leq 1$ term shows the effect on output due to inefficiency. The effect of the budget constraint on output can be examined as before (that is, as in the case without inefficiency). ${ }^{8}$

Technical inefficiency is modelled using the $\mathrm{SFA}^{9}$. Accordingly, the stochastic IPF is specified as follows:

$$
y=\psi(\mathbf{w} ; C ; \mathbf{z}) e^{(v-u)}
$$

where $\psi(\cdot)$ represents the indirect production frontier, $v$ is a producer-specific random noise component and $u \geq 0$ represents technical inefficiency. Accordingly, the IPF defines the maximum possible output given fixed input quantities, variable input prices and the budget for the purchase of variable inputs.

To impose minimum a priori restrictions on the underlying production technology, we use a parametric flexible functional form to approximate the IPF in equation (5). The translog functional form is chosen because, in contrast to the Cobb-Douglas form, it imposes no a priori restrictions on any of the elasticities. After introducing the firm, fixed and variable input subscripts, $i(i \in I), m(m \in M)$ and $j(j \in J)$, respectively, the IPF specification of

8 In this paper, we do not model the relationship between technical efficiency and budget constraints. We suppose that this relationship, if it exists at all, is likely to be complex and will differ from farm to farm. It might be that the presence of a budget constraint makes a farm more technically efficient, because then the farm is less likely to waste its resources. Conversely, if technical inefficiency is regarded as dependent on managerial ability, it might be assumed that expenditure constraint is positively correlated with technical inefficiency. However, since $\lambda$ measures the extent of expenditure constraint and it is determined only after the model is estimated, one cannot model the relationship between $\lambda$ and $u$ theoretically (prior to estimation). This relationship can, however, be examined ex-post.

9 Alternatively, DEA could be employed. In contrast to SFA, no functional form for the frontier is imposed on the data in DEA. However, DEA is a deterministic approach and thus does not allow for the possibility of noisy data. Consequently, in DEA, all deviations from the frontier are considered as due to inefficiency. SFA, an econometric approach, attempts to distinguish the effect of noise from that of inefficiency. Therefore, SFA is considered to be a more appropriate approach for an environment characterised by output uncertainty due to random exogenous shocks beyond farmers' control. 
the stochastic frontier assumes the following form ${ }^{10}$ :

$$
\begin{aligned}
\ln y_{i}= & \alpha_{0}+\sum_{j=1}^{J} \alpha_{j} \ln w_{j i}+\sum_{m=1}^{M} \alpha_{m} \ln z_{m i}+\alpha_{C} \ln C_{i} \\
& +\frac{1}{2}\left\{\sum_{k=1}^{J} \sum_{j=1}^{J} \alpha_{j k} \ln w_{j i} \ln w_{k i}+\alpha_{C C}\left(\ln C_{i}\right)^{2}+\sum_{l=1}^{M} \sum_{m=1}^{M} \alpha_{m l} \ln z_{m i} \ln z_{l i}\right\} \\
& +\sum_{m=1}^{M} \sum_{j=1}^{J} \alpha_{j m} \ln w_{j i} \ln z_{m i}+\sum_{j=1}^{J} \alpha_{j C} \ln w_{j i} \ln C_{i}+\sum_{m=1}^{F} \alpha_{m C} \\
& \ln z_{m i} \ln C_{i}+v_{i}-u_{i} .
\end{aligned}
$$

In addition to the usual symmetry restrictions on the coefficients, $\beta_{j k}, \mu_{m l}, \gamma_{j m}$, economic theory states that the IPF is homogeneous of degree zero in input prices and $C$ (Chambers, 1982). This gives rise to the following set of restrictions on the parameters of the model:

$$
\begin{gathered}
\sum_{j=1}^{J} \alpha_{j}+\alpha_{C}=0 ; \\
\sum_{j=1}^{J} \alpha_{j k}+\alpha_{j C}=0, \quad \forall j=1, \ldots, J ; \\
\sum_{j=1}^{J} \alpha_{j m}+\alpha_{m C}=0, \quad \forall m=1, \ldots, M ; \\
\sum_{j=1}^{J} \alpha_{j C}+\alpha_{C C}=0 .
\end{gathered}
$$

These homogeneity conditions can be easily imposed, for example, by scaling (dividing) input prices and expenditure by one of the input prices. That is, all prices and $C$ are to be normalised in terms of one input price. Alternatively, one can scale all the input prices by $C$.

The constant-cost demand function for the $j$ th variable input can be derived from the IPF by using Roy's identity (Chambers, 1982):

$$
x_{j}=-\frac{\partial y}{\partial w_{j}} / \frac{\partial y}{\partial C} \text {. }
$$

Using this equation, the share of the $j$ th input in total variable cost can be

10 This formulation is for a cross-sectional model. The extension of it to the panel data case is presented in Appendix 2. 
determined as

$$
S_{j}=-\frac{\partial \ln y}{\partial \ln w_{i}} / \frac{\partial \ln y}{\partial \ln C} \equiv-\frac{\varepsilon_{y j}}{\varepsilon_{y C}},
$$

where $\varepsilon_{y C}$ denotes the output elasticity with respect to a change in the producer's budget and $\varepsilon_{y j}$ denotes the output elasticity with respect to a change in the price of input $j$. In general, IPF should be concave in expenditure and convex in prices, i.e. the sign of $\varepsilon_{y C}$ should be positive (indicating an increase in production as a result of budget constraints' relief), whereas the sign of $\varepsilon_{y j}$ should be negative (implying a reduction of budget in real terms, if input prices increase).

The full econometric specification of the model can be found in Appendix B.

\section{Estimation procedure}

Our interest is to estimate not only the parameters of the IPF but also inefficiency, which is assumed to be distributed randomly subject to a given distribution. The IPF with technical inefficiency can be estimated as a stochastic frontier model (Kumbhakar and Lovell, 2000). Two approaches are possible. The first approach (similar to the estimating the cost function) considers the IPF alone (i.e. without share equations). The second approach (similar to the estimation of the cost system, i.e. the cost function and cost share equations) is to consider the IPF and the share equations in (17) and to estimate them jointly using a system approach.

With the first approach, it is possible to estimate the IPF parameters and technical efficiency in a one-step procedure by applying the maximum likelihood (ML) method. The ML method typically assumes that (i) $u$ is i.i.d. $N\left(0, \sigma_{u}^{2}\right)$ truncated at zero from below; (ii) $v$ is i.i.d. $N\left(0, \sigma_{v}^{2}\right)$; (iii) $u$ and $v$ are independent of each other. With the second approach, the ML method can also be used; in addition to the assumptions listed above, it also assumes that the vector of the disturbance terms from the respective share equations, $\mathbf{r}=\left(r_{1}, \ldots r_{J-1}\right)$, follows a multivariate normal distribution with zero mean and a constant variance-covariance matrix, and that $u$ and $v$ are independent of $r$. Details of both approaches can be found in Kumbhakar and Lovell (2000: 131-175). ${ }^{11}$ If the distributional assumptions for the stochastic error components are correct, the ML estimates based on both approaches are consistent and asymptotically efficient. However, incorrect distributional assumptions can cause inconsistent parameter estimates of the production technology represented by the IPF.

Thus, to guard against possible misspecification of distributional assumptions, it is often better to use a two-step procedure in which the estimators in the first step are free from distributional assumptions. In the second step,

11 Since the present set up is mathematically similar to the cost function formulation, we leave the details to the readers to work out. Note that the IPF system (IPF plus the share equations) is much more complex (non-linear) than the cost system discussed in Kumbhakar and Lovell (2000) and Kumbhakar and Tsionas (2005). 
one cannot avoid making distributional assumptions to estimate inefficiency. However, in this case the distributional assumptions for the inefficiency and noise terms do not affect the IPF parameter estimates in the first step.

Furthermore, if $C$ is endogenous, the ML estimates are inconsistent. The ML method cannot handle endogenous regressors in a straightforward manner. Thus, similar to Guan et al. (2009) we suggest controlling for the endogeneity by applying a two-step procedure. In the first step, we use an estimation technique that can handle endogenous regressors (i.e. instrumental variable (IV) approach). In the second step, we employ the ML method to estimate inefficiency using the residuals from the IPF from the first step. In fact, we extend the Guan et al. (2009) approach in a system framework. ${ }^{12}$

\subsection{First step}

In the first-step, we make some adjustments to obtain a disturbance term with zero mean. We rewrite the composed error term in the IPF as $e_{i t}=v_{i t}-u_{i t}=$ $v_{i t}-\left(u_{i t}-E\left(u_{i t}\right)\right)-E\left(u_{i t}\right)=e_{i t}^{*}-E\left(u_{i t}\right)$ so that the mean of $e_{i t}^{*}$ is zero. The $E\left(u_{i t}\right)$ term is subsumed into the intercept if its mean is constant. This gives us a system of simultaneous equations that can be easily estimated without making any specific distributional assumptions about $e_{i t}^{*}$ and $r_{j i t}$, except that they are distributed with mean zero and constant variances. These covariances between these disturbances are not restricted to be zero.

If $C$ is exogenous, then the system can be estimated using the seemingly unrelated regression (SUR) procedure. However, if $C$ happens to be endogenous, we have to use a system of IV approach. The instrument for $C$ is the predicted value of $C$ from a regression of it on all the exogenous variables used in the system. ${ }^{13}$ We do this because in a micro application like ours, it is difficult to find variables that are good instruments for $C$ but are not used in the model.

\subsection{Second step}

Since technical inefficiency appears only in the IPF equation, and does not influence the share equations, we use the residuals from the IPF from the first step to recover parameters associated with $u$ as well as obtain observationspecific estimates of $u$. To accomplish this, we make some distributional assumptions that are standard in the stochastic frontier literature (see Kumbhakar and Lovell, 2000). These are: (i) $u$ is i.i.d. $N\left(0, \sigma_{u}^{2}\right)$ truncated at zero from below (half normal); (ii) $v$ is i.i.d. $N\left(0, \sigma_{v}^{2}\right)$ and (iii) $u$ and $v$ are distributed independent of each other. Based on these assumptions, the probability density function of $(v-u)$ can be easily obtained using the convolution

12 Guan et al. (2009) treat the endogeneity problem in a single equation model.

13 The exogenous variables used to predict $C$ include all the exogenous variables in the IPF plus the exogenous variables used to explain inefficiency. Note that these latter variables are not used in the first step. 
formula. The model in the second stage is:

$$
\hat{e}_{i t}=\alpha_{0}+v_{i t}-u_{i t}
$$

where $\hat{e}_{i t}$ is the residual from the IPF. The ML method can be used on the model in equation (19) to obtain estimates of $\alpha_{0}, \sigma_{u}^{2}, \sigma_{v}^{2}$.

Our interest is, however, not only in estimating inefficiency but also in explaining inefficiency in terms of relevant farms' characteristics. This can be done by making (i) the mean of $u$ a function of the exogeneous variables, (ii) the variance of $u\left(\sigma_{u}^{2}\right)$ a function of the exogeneous variables and (iii) both the mean and variance functions of exogeneous variables. These specifications allow differences in inefficiency scores to be explained by certain exogeneous variables and, respectively, to calculate the marginal effect of an exogeneous variable on inefficiency. These models are discussed in detail in Kumbhakar and Lovell (2000) as well as in Wang (2002).

There are some differences between our present model and those discussed in Kumbhakar and Lovell (2000) and Wang (2002). First, their models involve a single equation (production function) whereas we have a system of equations. Second, we have an additional endogenous variable $(C)$ as a regressor in the system. This makes the ML estimators inconsistent (see Guan et al. (2009) for details on this in the context of a single equation model). The system approach discussed in Kumbhakar and Tsionas (2005) will also give inconsistent parameter estimates if one or more of the regressors are endogenous. Because of this we use the two-step approach suggested by Guan et al. (2009) and apply Wang's model (2002) in the second step.

\section{Data}

To estimate the model proposed in the preceding section, we employ data obtained from a farm survey of 90 agricultural enterprises in the Oroel, Samara and Stavropol regions. In addition to having farm accounting data from 1999 to 2003, the data also incorporate the results of structured interviews with farm managers. After excluding farms with a high level of specialisation in a particular production line, we formed an unbalanced panel data set containing 347 observations from a total of 73 farms. In addition, the study utilises data on the price indices for agricultural output and inputs as provided by the Russian State Statistical Agency Rosstat (Rosstat 2005).

We define farm output as annual farm revenue from agricultural production $(Y)$. Land $(L)$ and fixed capital $(K)$ are regarded as quasi-fixed inputs. The quantity of land is measured in hectares of area sown, adjusted by the farm's average soil fertility index. The value of fixed assets used in agricultural production is used as proxy for capital. ${ }^{14}$

14 All monetary variables are measured in RUB 1,000. Farming revenue and the capital stock value were adjusted to the price level of 2003 by employing annual price indices for agricultural output and machines in agriculture, respectively. Note that none of these variables appear in the 
We distinguish between four major variable inputs: labour, fertiliser, fuel and other variable inputs including plant protection, seed, electricity, etc. Since we did not have any prices for inputs from the last group (i.e. other variable inputs), we aggregated these inputs with the fuel input. Accordingly, we consider three cost shares in our empirical analysis: those of labour and fertiliser, and an aggregate cost share for fuel and other variable inputs (labelled as fuel). The cost shares are calculated as the ratio of the respective input costs to the total expenditure on them.

We measured labour prices by the farms' average annual labour wages $\left(w^{L}\right)$ in RUB 1,000 per farm worker engaged in agricultural production. To represent fertiliser prices, we constructed an aggregate fertiliser price index ${ }^{15}$ calculated as a ratio of farm expenditure for mineral fertilisers in RUB 1,000 to the total active substance in all fertiliser types, measured in physical units, used on the farm. Fuel prices were obtained by dividing fuel expenditure by the total amount of fuel, measured in physical units, used on the farm. Since no data were available for farms' predetermined expenditure, we followed Lee and Chambers (1986) and defined the expenditure variable as the observed expenditure on variable inputs in individual years. ${ }^{16}$ Fuel prices were used to normalise the observed expenditure volume as well as labour and fertiliser prices. ${ }^{17}$

The variables used to explain inefficiency are: farm age/farmer's managerial experience $\left(q^{\text {age }}\right)$, extent of the manager's ownership stake $\left(q^{\text {own }}\right)$, size $\left(q^{\text {size }}\right)$, initial technology level $\left(q^{\text {tech99 }}\right)$, managerial competence $\left(q^{\text {manag }}\right)$, diversification level $\left(q^{\text {div }}\right)$, and severity of production risk $\left(q^{\text {risk }}\right) .{ }^{18}$ All exogenous variables were constructed using the results of the factor analysis conducted by Bokusheva et al. (2007) based on the same data as in the present study. ${ }^{19}$ The relevant factor solution explains a substantial part of the variation (75.5 per cent) in the original data set, which contained 31 farm characteristics related to enterprise organisation, managerial characteristics, productionrelated characteristics and the farm's business environment. Accordingly, we expect these farm characteristics to explain differences in the farms' technical efficiency. In particular, the extent of the managers' ownership stake in agricultural enterprises can influence their incentives to improve farm performance, thereby indicating a positive effect of this factor on technical

regressions as raw nominal amounts, but always as ratios or some other money-unit-free form. Thus, it is not necessary to use a deflator to convert them in real terms.

15 We constructed an aggregate fertiliser price index by dividing each farm's total fertiliser cost by the physical amount of fertiliser used, calculated as the sum of the active substances in different types of fertiliser.

16 Descriptive statistics for the variables employed to specify the IPF can be found in Table A2.

17 The total expenditure volume and variable input prices are measured in nominal prices. Since these variables are normalised by nominal fuel prices for the model estimation, no deflation was necessary with regard to these variables.

18 These variables were also used to explain the heteroscedasticity in the noise term.

19 The description of the relevant factors in terms of variables with significant factor loadings can be found in Table A3. 
efficiency. The level of managerial competence in agricultural enterprises should positively influence farms' organisational and technological procedures, which in turn would imply a positive impact on technical efficiency. Older farms are more likely to have well-established administrative structures. From this point of view, farm age should have a positive effect on farm productivity. However, newly established farms might be more entrepreneurial than their older counterparts; indeed, they can enhance their performance by introducing innovative production practices. Considering this, our estimates should provide empirical evidence on which of these two effects has been prevailing in Russian farms recently. The effect of farm size on technical efficiency might be rather diffuse; we suppose that farms in the lower and higher tails of the distribution (i.e. farms operating at either too small or too large a scale) might be less efficient than farms in between. These nonmonotonic efficiency effects can be revealed by applying the methodology suggested by Wang $(2002,2005)$. The effect of risk and diversification is assumed to be rather negative than positive. If risk plays an important role in decision-making, farms might purposely use inputs inefficiently to reduce their risk exposure. We employed all mentioned exogenous variables to explain also the heteroscedasticity in the disturbance term and as the exogeneous variables in the regression model, which was estimated to explain the extent of the farms' budget constraints.

\section{Estimation results}

Table 1 illustrates the IPF estimates for the farms considered in this analysis. To account for possible regional differences, we introduced dummy variables for three selected regions ${ }^{20}$ into the model. Although only one quarter of all parameters have significant estimates ${ }^{21}$ in the translog model specification, a Cobb-Douglas model specification is rejected against it at the 1 per cent level of significance using the standard likelihood ratio test.

The partial elasticities for the quasi-fixed inputs, i.e. land and capital, are positive ( 0.30 and 0.24 at the mean sample values, respectively). The output supply elasticity with respect to the farm budget for variable inputs equals 0.99 on average, indicating that output is expected to rise by 0.99 per cent for a 1 per cent increase in budget. The output supply elasticities with respect to fertiliser and labour are 0.29 and 0.37 , respectively. Consequently, the output supply elasticity of fuel and other variable inputs equals $0.34{ }^{22}$ These results show that farm output is much more sensitive to

20 The IPF constant term coefficient is the intercept estimate for farms in the Oroel region. The coefficient estimates for the dummy variables show differences between the intercept estimates for farms from Samara and Stavropol, respectively, and that of farms from Oroel.

21 This relatively small number of significant parameter estimates can be explained by the fact that in general standard errors in IV and GMM models tend to be larger than those from OLS and SUR.

22 The output supply elasticity for the variable input used for the input price normalisation (in our case: fuel and further variable inputs) can be calculated as the difference between the output 
Table 1. IPF parameter estimates (GMM)

\begin{tabular}{lrrlrr}
\hline Variable & $\begin{array}{l}\text { Coefficient } \\
\text { estimate }\end{array}$ & $t$-Value & Variable & $\begin{array}{l}\text { Coefficient } \\
\text { estimate }\end{array}$ & $t$-Value \\
\hline Constant & 0.982 & 0.310 & $w^{F} * w^{F}$ & -0.002 & -0.340 \\
Dummy & -0.096 & -1.650 & $w^{L} * w^{L}$ & -0.027 & -2.790 \\
$\quad$ Samara & & & & & \\
Dummy & 0.082 & 1.430 & $w^{F} * w^{L}$ & -0.002 & -0.470 \\
$\quad$ Stavropol & & & & & \\
$w^{F}$ & -0.033 & -0.850 & $C^{2}$ & 0.026 & 0.680 \\
$w^{L}$ & -0.192 & -1.950 & Land $*$ Land & 0.107 & 1.100 \\
$C$ & 0.343 & 0.920 & Capital $*$ Capital & 0.031 & 0.770 \\
Land & 0.012 & 0.020 & Land $*$ Capital & -0.042 & -0.360 \\
Capital & 0.093 & 0.310 & $w^{F} *$ Land & -0.002 & -0.440 \\
$t$ & 0.030 & 0.160 & $w^{F} *$ Capital & 0.008 & 2.370 \\
$t^{2}$ & 0.026 & 2.310 & $w^{L} *$ Land & 0.021 & 1.790 \\
$w^{F} * t$ & 0.000 & 0.210 & $w^{L} *$ Capital & -0.011 & -1.330 \\
$w^{L} * t$ & 0.004 & 0.990 & $w^{F} * C$ & -0.009 & -2.470 \\
$C^{*} t$ & -0.015 & -1.030 & $w^{L} * C$ & 0.002 & 0.160 \\
Land $* t$ & 0.024 & 1.030 & Land $* C$ & -0.024 & -0.600 \\
Capital ${ }^{L} t$ & -0.013 & -0.730 & Capital $* C$ & 0.023 & 0.780 \\
\hline
\end{tabular}

Note: $w^{F}$, price of fertiliser; $w^{L}$, wage; $C$, expenditure.

Source: Authors' estimates. Note that the usual diagnostics are not available in GMM. The squared correlation between actual and predicted outputs (the indicator corresponding to $R^{2}$ ) is found to be 0.91 .

changes in the availability of variable inputs compared with changes in the quasi-fixed inputs. Moreover, farms' sensitivity to the availability of additional funds for purchasing variable inputs does not seem to decrease during the sample period since the coefficient of the cross-product term $\left(C^{*} t\right)$ is not significantly different from zero.

Table 2 presents our results regarding expenditure constraints and related output losses in the study farms. We calculated the level of expenditure constraint for the individual farms as the difference between the desired budget and the farm's observed expenditures. ${ }^{23}$ The results show that 331 of 347 farm observations (i.e. 95 per cent) faced expenditure constraints during the sample period. The average level of actual farm expenditures was, on average, 24 per cent lower than the desired level; half the farms are expenditure-constrained by more than 22 per cent. In addition, according to our calculations, the expenditure constraints have caused an output loss of 20 per cent, on average.

Technical inefficiency presents another source of output loss for farms. The average technical inefficiency of farms in the sample is 0.13 . This means that

supply elasticity with respect to the farm budget and the output supply elasticities of all remaining variable inputs employed in the IPF.

23 We determined the desired budget level as described in Section 2.1. 
Table 2. Expenditure constraints, output loss and technical efficiency estimates ${ }^{\mathrm{a}}$

\begin{tabular}{rllll}
\hline & Lambda & $\begin{array}{l}\text { Expenditure } \\
\text { constraints }\left(C^{*}-C\right) / C\end{array}$ & $\begin{array}{l}\text { Output loss } \\
\left(Y^{*}-Y^{\mathrm{IPF}}\right) / Y^{\mathrm{IPF} b}\end{array}$ & $\begin{array}{l}\text { Technical } \\
\text { efficiency }\end{array}$ \\
\hline Mean & 1.09 & 0.24 & 0.20 & 0.87 \\
SD & 0.04 & 0.12 & 0.12 & 0.07 \\
Max. & 1.18 & 0.68 & 0.80 & 0.97 \\
Min. & 1.00 & 0.00 & 0.00 & 0.59 \\
Quantiles & $\%)$ & & & \\
99 & 1.17 & 0.55 & 0.55 & 0.97 \\
95 & 1.14 & 0.47 & 0.42 & 0.96 \\
90 & 1.13 & 0.41 & 0.38 & 0.95 \\
75 & 1.11 & 0.30 & 0.27 & 0.93 \\
50 & 1.08 & 0.22 & 0.18 & 0.9 \\
25 & 1.06 & 0.15 & 0.11 & 0.84 \\
10 & 1.04 & 0.10 & 0.07 & 0.76 \\
5 & 1.03 & 0.07 & 0.05 & 0.72 \\
1 & 1.00 & 0.01 & 0.01 & 0.66 \\
\hline
\end{tabular}

Source: Authors' estimates.

${ }^{a}$ Estimates for the constrained farms only.

${ }^{\mathrm{b}} Y^{\mathrm{IPF}}$ is the constrained output level (deterministic part of the IPF); $Y^{*}$ is the unconstrained output level (calculated by replacing the observed farm's expenditure $C$ by the desired budget level $C^{*}$ ).

output is reduced, on average, by 13 per cent due to technical inefficiency. Figure 2 shows the frequency distribution of the technical inefficiency estimates. Technical inefficiency estimates for most of the farms are within the range of 5 to 20 per cent. Output loss due to technical inefficiency can be obtained from the last column of Table 2, as $1-$ TE.

A comparison of the average farm output loss due to technical inefficiency and budget constraints shows that a larger part of output loss is caused by the budget constraints of the farms. But we have found only a low association between the two sources of output loss; the coefficient of correlation

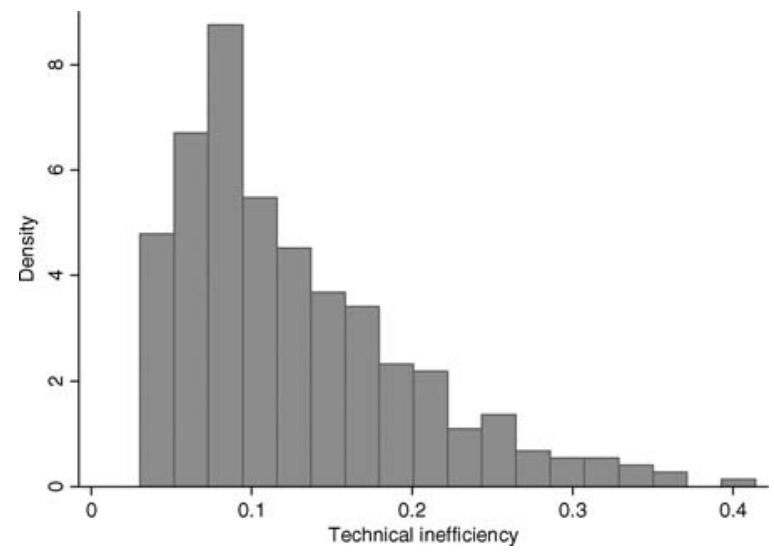

Figure 2. Distribution of technical inefficiency. Source: Authors' estimates. 
between technical inefficiency and under-performance due to a budget constraint is 0.14 .

Table 3 presents average output loss for the whole sample as well as the regions for individual years. Output loss due to budget constraints and technical inefficiency assessed for the whole sample seems to decrease slightly over the sample period. Nonetheless, we observe some differences across regions. While budget constraints and technical efficiency have a tendency to decrease in Samara over the period, no clear trend emerges for the two other regions. Furthermore, though budget constraints have been the major source of output loss in all three regions, they have been especially pronounced in Oroel. These results suggest the presence of regional differences in the business environment of the farms. Additionally, there is a considerable variation in output loss across farms within individual regions, which hardly reduces over time. This indicates that independent of the general economic situation in Russia and the regional business environment, farm characteristics have a considerable impact on performance and access to finance.

In the second step, we estimated the basic model without heteroscedasticity in both $v$ and $u$. This model specification was, however, rejected against the more general model with heteroscedasticity in $u$ and $v{ }^{24}$ The parameter estimates, reported in Table 4, show that managerial competence and technology level in 1999 have negative coefficient estimates. This implies that these two farm characteristics reduce variability in technical efficiency across farms, thus negatively affecting the sample mean inefficiency. ${ }^{25}$ While individual farm characteristics such as farm age and ownership seem to reduce variability in output, ceteris paribus, management competencies were found to increase output variance. In our view, this suggests that farms with higher managerial competences may rely on other options of risk management than only technological ones (e.g. crop insurance, credit and maintaining financial reserves).

Finally, Table 5 presents the estimation results obtained by regressing the assessed level of the individual farms' budget constraints $\left(C_{i}^{*}-C_{i}\right) / C_{i}$ on the selected farm characteristics. Only two variables - farm ownership and size are found to have a significant effect on farms' budget constraints. Jointly with time dummies, they explain 48 per cent of the variation in the individual farms' budget constraints $\left(R^{2}=0.48\right)$. Both factors influence budget constraints negatively. This indicates that farms with no or only a minor manager-ownership stake have been more likely to experience budget constraints during the study period. This is in line with the principal-agent hypothesis: farm managers (non-owners) could be less concerned about reducing farms' expenditure constraints. Input decisions of larger farms also seem to be less affected by

24 The model specification allowing the mean of technical inefficiency to be a function of exogeneous variables was rejected against the basic model formulation.

25 This is because $E(u)=\sqrt{ } 2 / \pi \sigma_{u}(q)$ (where $\pi=3.1416$ ). Thus, if $q$ affects $\sigma_{u}$ negatively, the mean inefficiency reduces when $q$ increases. We specified $\sigma_{u}$ and $\sigma_{v}$ as exponential functions of the $q$ variables and found that the marginal effects on the expected technical inefficiency have been decreasing with respect to both variables - managerial competence and also level of technology. 
Table 3. Assessment of farms' average output loss (in per cent) due to budget constraints (BC) and technical inefficiency (TI) across years and regions ${ }^{\mathrm{a}}$

\begin{tabular}{|c|c|c|c|c|c|c|c|c|}
\hline & \multicolumn{2}{|c|}{ Whole sample } & \multicolumn{2}{|c|}{ Oroel sub-sample } & \multicolumn{2}{|c|}{ Samara sub-sample } & \multicolumn{2}{|c|}{ Stavropol sub-sample } \\
\hline & $\mathrm{BC}$ & $\mathrm{TI}$ & $\mathrm{BC}$ & TI & $\mathrm{BC}$ & TI & $\mathrm{BC}$ & TI \\
\hline 1999 & $0.22(0.14)$ & $0.13(0.09)$ & $0.30(0.12)$ & $0.13(0.08)$ & $0.21(0.17)$ & $0.17(0.09)$ & $0.16(0.07)$ & $0.10(0.07)$ \\
\hline 2000 & $0.18(0.13)$ & $0.13(0.08)$ & $0.24(0.15)$ & $0.12(0.06)$ & $0.16(0.12)$ & $0.15(0.07)$ & $0.14(0.06)$ & $0.13(0.09)$ \\
\hline 2001 & $0.18(0.12)$ & $0.13(0.07)$ & $0.23(0.14)$ & $0.13(0.08)$ & $0.16(0.13)$ & $0.13(0.07)$ & $0.14(0.08)$ & $0.13(0.08)$ \\
\hline 2002 & $0.19(0.13)$ & $0.13(0.07)$ & $0.24(0.15)$ & $0.13(0.08)$ & $0.19(0.15)$ & $0.15(0.08)$ & $0.14(0.07)$ & $0.11(0.06)$ \\
\hline 2003 & $0.18(0.14)$ & $0.12(0.07)$ & $0.26(0.15)$ & $0.13(0.07)$ & $0.11(0.12)$ & $0.12(0.07)$ & $0.17(0.09)$ & $0.12(0.06)$ \\
\hline
\end{tabular}

Source: Authors' estimates.

${ }^{\text {aa }}$ Standard deviations are shown in parentheses. 
Table 4. Parameter estimates of the frontier model (second stage)

\begin{tabular}{ccr}
\hline Variable & Coefficient estimate & $t$-Value \\
\hline $\begin{array}{l}\text { Frontier } \\
\text { Const }\end{array}$ & 0.15 & \\
$\sigma_{u}$ & & 3.34 \\
Const & -3.78 & -5.13 \\
$q^{\text {manag }}$ & -0.53 & -2.16 \\
$q^{\text {tech99 }}$ & -1.13 & -3.39 \\
$\sigma_{v}$ & & -21.09 \\
Const & -2.43 & -2.08 \\
$q^{\text {age }}$ & -0.19 & -3.13 \\
$q^{\text {own }}$ & -0.28 & 3.85 \\
$q^{\text {manag }}$ & 0.37 & \\
LR statistic & $95.79^{*}$ & \\
\hline
\end{tabular}

Source: Authors' estimates.

The individual coefficients are all statistically significant at the 1 per cent level. The likelihood ratio test shows that heteroscedasticity cannot be rejected at the 1 per cent level of significance (*).

Table 5. Parameter estimates of factors influencing farms' budget constraints

\begin{tabular}{lrr}
\hline Variable & Coefficient estimate & $t$-Value \\
\hline Constant & 0.26 & 19.40 \\
d_2000 & -0.03 & -1.83 \\
d_2001 & -0.04 & -2.39 \\
d_2002 & -0.02 & -1.34 \\
d_2003 & -0.03 & -1.52 \\
$q^{\text {own }}$ & -0.02 & -4.39 \\
$q^{\text {size }}$ & -0.09 & -15.40 \\
$R^{2}$ & 0.52 & \\
$F$-statistics & $44.7^{\mathrm{a}}$ & \\
\hline
\end{tabular}

Source: Authors' estimates.

${ }^{\text {a }}$ The model is significant at the 1 per cent level.

budget constraints. This result is quite reasonable: first, large farms might experience lower transaction costs when applying for external finance; second, they can maintain larger financial reserves than their smaller counterparts.

\section{Conclusions}

In this study we applied the IPF approach to analyse producers' output and input allocation choices under expenditure constraints. By deriving the conditions for optimal input use, we determined the effect of expenditure constraints on producer output. This allowed us to identify the output loss due to the presence of budget constraints. An additional source of output loss considered in our analysis was technical inefficiency. To estimate producers' 
technical efficiency under expenditure constraints, we defined IPF as the production frontier, thereby allowing it to assess farm-underperformance due to both budget constraints and technical inefficiencies.

The empirical analysis shows that most (95 per cent) of the sample farms in the three regions studied were expenditure constrained during 1999-2003, with farm actual expenditure being on average 24 per cent lower than the desired level. The budget constraints caused an average output loss of 20 per cent. Average technical inefficiency of farms was found to be 13 per cent. This indicates that even in the presence of imperfections in financial markets, Russian farms have the potential to increase their output, ceteris paribus. Managerial competence and the level of technology were found to determine significantly the farm technical efficiency. Comparing the extent of the output losses due to expenditure constraints and technical inefficiency, we conclude that Russian farms' production possibilities at present are primarily determined by external conditions rather than by their internal organisation. Thus, the governmental policies, in our view, should be directed principally towards advancements in the external environment of farms, e.g. by improving farms' access to finance and input and output markets.

Our estimates of technical inefficiency are rather moderate compared with those of previous analyses for Russia at the farm level for the corresponding periods (Grazhdaninova and Lerman, 2005; Grazhdaninova and Brock, 2004; Bokusheva and Hockmann, 2006). This is likely to be related to the fact that our study tries to incorporate peculiarities in the farms' internal and external environment when representing the production technology. In particular, we explicitly introduce output (profit) maximisation behaviour when modelling producers' input allocation decisions and allow the possibility that producers might face borrowing constraints.

In a broader context this study highlights two important issues that are often ignored in the efficiency studies, viz., endogeneity of inputs and the presence of borrowing constraints. If the inputs are endogenous, the estimates from the standard production function as well as stochastic production frontier are biased. Consequently, estimated inefficiencies are likely to be incorrect (because these are based on biased parameter estimates). Similarly, ignoring expenditure constraints might lead one to conclude that producers are inefficient in allocating inputs (allocative inefficiency). Although allocative inefficiency is not formally introduced in this paper, the error terms in the share equations (first-order conditions) can be interpreted as allocative inefficiency.

\section{Acknowledgements}

The authors would like to thank three anonymous reviewers and the Editors for their valuable comments. The study was initiated during a research stay of Raushan Bokusheva at the State University of New York at Binghamton. She greatly acknowledges the financial support of the German Research Foundation (DFG) and the Leibniz Institute of Agricultural Development in Central and Eastern Europe (IAMO). 


\section{References}

Amemiya, T. (1985). Advanced Econometrics. Cambridge, MA: Harvard University Press.

Arnade, C. and Gopinath, M. (2000). Financial constraints and output targets in Russian agricultural production. Journal of International Development 12: 71-84.

Arnade, C. and Trueblood, M. (2002). Estimating a profit function in the presence of inefficiency: an application to Russian agriculture. Journal of Agricultural and Resource Economics 27: 94-113.

Bezlepkina, I. V. (2004). Microeconomic analysis of Russian agricultural enterprises. Ph.D. thesis, Wageningen University, The Netherlands.

Bezlepkina, I., Oude Lansink, A. and Oskam, A. J. (2005). Effects of subsidies in Russian dairy farming. Agricultural Economics 33: 277-288.

Bokusheva, R., Bezlepkina, I. and Oude Lansink, A. (2009). Exploring investment behavior of farms in transition: the case of Russian agriculture. Journal of Agricultural Economics 60: 436-464.

Bokusheva, R., Valentinov, V. and Anpilogova, V. (2007). The investment behavior of Russian farms. Post-Communist Economies 19: 53-71.

Bokusheva, R. and Hockmann, H. (2006). Production risk and technical inefficiency in Russian agriculture. European Review of Agricultural Economics 33: 93-118.

Chambers, R. G. (1982). Duality, the output effect, and applied comparative statics. American Journal of Agricultural Economics 64: 152-156.

Ferguson, C. E. (1969). Microeconomic Theory, revised edition. Homewood, Illinois: Richard C. Irvin, Inc.

Gallant, A. R. (1987). Nonlinear Statistical Models. New York: John Wiley.

Government of Russia (2001). On the implementation and the conditions of the implementation of restructuring farm debts (main debts, interests and fines) to federal budgetary and non-budgetary funds. Resolution of the Government of Russian Federation N 458, 8 June 2001. Moscow.

Grazhdaninova, M. and Brock, G. (2004). Grain and sunflower on Russian farms in 2001: how efficient is crop production? Post-Communist Economies 16: 297-305.

Grazhdaninova, M. and Lerman, Z. (2005). Allocative and technical efficiency of corporate farms in Russia. Comparative Economic Studies 47: 200-213.

Guan, Z., Kumbhakar, S. C., Myers, R. J. and Oude Lansink, A. (2009). Measuring excess capital capacity in agricultural production. American Journal of Agricultural Economics 91(3): 765-776.

Kumbhakar, S. C. and Lovell, C. A. K. (2000). Stochastic Frontier Analysis. Cambridge: Cambridge University Press.

Kumbhakar, S. C. and Tsionas, E. G. (2005). Measuring technical and allocative inefficiency in the translog cost system: a Bayesian approach. Journal of Econometrics 126: $355-384$.

Latruffe, L. (2005). The impact of credit market imperfections on farm investment in Poland. Post-Communist Economies 17: 349-362.

Lee, H. and Chambers, R. G. (1986). Expenditure constraints and profit maximization in U.S. agriculture. American Journal of Agricultural Economics 68: 857-865. 
Minselkhoz (2008). Agropromyshlennyi kompleks Rossii 2006. [Russian agro-food sector in 2006, in Russian]. Electroic database of the Ministry of Agriculture of the Russian Federation. http://www.mcx.ru. Accessed 20 July 202008.

Osborne, S. and Trueblood, M. A. (2002). An examination of economic efficiency of Russian crop output in the reform period. In: E. Schulze, E. Knappe, E., Serova and P. Wehrheim (eds), Studies on the Agricultural and Food Sector in Central and Eastern Europe 21. Success and Failures of Transition - The Russian Agriculture between Fall and Resurrection. Halle/Saale: Agrimedia, 66-90.

Rosstat (2005). Russian Statistical Yearbook. Moscow, Russia: Russian State Statistical Agency.

Rosstat (annual editions from 1997 to 2007) Selskoe hozjajstvo Rossii Statistical Yearbook: Agriculture in Russia. Moscow, Russia: Russian Statistical Agency (Rosstat).

Sedik, D., Trueblood, M. and Arnade, C. (1999). Corporate farm performance in Russia, 1991-95: an efficiency analysis. Journal of Comparative Economics 27: 514-533.

Sotnikov, S. (1998). Evaluating the effects of price and trade liberalisation on the technical efficiency of agricultural production in a transition economy: the case of Russia. European Review of Agricultural Economics 25: 412-431.

Wang, H. J. (2002). Heteroskedasticity and non-monotonic efficiency effects of a stochastic frontier model. Journal of Productivity Analysis 18: 241-253.

Wang, H. J. (2005). Stata program for 'heteroskedasticity and non-monotonic efficiency effects of a stochastic frontier model'. http://homepage.ntu.edu.tw/ wangh/. Accessed May 27, 2009.

\section{Appendix A}

Table A1. Share of (total) subsidies in total output of Russian corporate farms

\begin{tabular}{llllllllllllllllll}
\hline & 1992 & 1993 & 1994 & 1995 & 1996 & 1997 & 1998 & 1999 & 2000 & 2001 & 2002 & 2003 & 2004 & 2005 & 2006 \\
\hline $\begin{array}{l}\text { Share of } \\
\text { subsidies } \\
\text { in total } \\
\text { output }\end{array}$ & 0.15 & 0.09 & 0.07 & 0.07 & 0.06 & 0.06 & 0.08 & 0.03 & 0.03 & 0.03 & 0.04 & 0.04 & 0.04 & 0.05 & 0.05 \\
\hline
\end{tabular}

Source: Authors' presentation based on the data as provided by Rosstat (Rosstat, 1997-2007) and Minselkhoz (2008, http://www.mcx.ru).

Table A2. Descriptive statistics of the IPF variables (1999-2003)

\begin{tabular}{|c|c|c|c|c|c|c|c|c|c|}
\hline & $\begin{array}{l}\text { Output } \\
1,000 \\
\text { RUB of } \\
2003\end{array}$ & $\begin{array}{l}\text { Land } \\
\text { (hectares } \\
\text { sown } \\
\text { adjusted } \\
\text { for soil } \\
\text { fertility) }\end{array}$ & $\begin{array}{l}\text { Capital } \\
1,000 \\
\text { RUB of } \\
2003\end{array}$ & $\begin{array}{l}\text { Observed } \\
\text { expenditure } \\
1,000 \mathrm{RUB}^{\mathrm{a}}\end{array}$ & $\begin{array}{l}\text { Labour } \\
\text { wages } \\
1,000 \\
\text { RUB } \\
\text { p.a. }^{\text {a }}\end{array}$ & $\begin{array}{l}\text { Fertiliser } \\
\text { price } \\
1,000 \\
\text { RUB per } \\
\text { ton }^{\mathrm{a}}\end{array}$ & $\begin{array}{l}\text { Fuel } \\
\text { price } \\
1,000 \\
\text { RUB } \\
\text { per } \\
\text { ton }^{\text {a }}\end{array}$ & $\begin{array}{l}\text { Labour } \\
\text { cost } \\
\text { share }\end{array}$ & $\begin{array}{l}\text { Fertiliser } \\
\text { cost share }\end{array}$ \\
\hline \multicolumn{10}{|l|}{1999} \\
\hline Mean & 35,400 & 3,361 & 39,554 & 15,738 & 10.25 & 3.17 & 3.63 & 0.25 & 0.07 \\
\hline SD & 52,401 & 2,822 & 35,437 & 16,856 & 2.58 & 1.36 & 1.31 & 0.10 & 0.07 \\
\hline Min. & 2,392 & 488 & 295 & 1,907 & 7.10 & 1.57 & 1.67 & 0.09 & 0.00 \\
\hline Max. & 294,557 & 12,842 & 183,975 & 77,319 & 19.93 & 7.47 & 8.90 & 0.50 & 0.42 \\
\hline
\end{tabular}


Table A2. Descriptive statistics of the IPF variables (1999-2003) (continued)

\begin{tabular}{|c|c|c|c|c|c|c|c|c|c|}
\hline & $\begin{array}{l}\text { Output } \\
1,000 \\
\text { RUB of } \\
2003\end{array}$ & $\begin{array}{l}\text { Land } \\
\text { (hectares } \\
\text { sown } \\
\text { adjusted } \\
\text { for soil } \\
\text { fertility) }\end{array}$ & $\begin{array}{l}\text { Capital } \\
1,000 \\
\text { RUB of } \\
2003\end{array}$ & $\begin{array}{l}\text { Observed } \\
\text { expenditure } \\
1,000 \mathrm{RUB}^{\mathrm{a}}\end{array}$ & $\begin{array}{l}\text { Labour } \\
\text { wages } \\
1,000 \\
\text { RUB } \\
\text { p.a. }\end{array}$ & $\begin{array}{l}\text { Fertiliser } \\
\text { price } \\
1,000 \\
\text { RUB per } \\
\text { ton }^{\mathrm{a}}\end{array}$ & $\begin{array}{l}\text { Fuel } \\
\text { price } \\
1,000 \\
\text { RUB } \\
\text { per } \\
\text { ton }^{\text {a }}\end{array}$ & $\begin{array}{l}\text { Labour } \\
\text { cost } \\
\text { share }\end{array}$ & $\begin{array}{l}\text { Fertiliser } \\
\text { cost share }\end{array}$ \\
\hline \multicolumn{10}{|l|}{2000} \\
\hline Mean & 34,933 & 3,611 & 52,906 & 22,561 & 13.68 & 3.61 & 4.74 & 0.24 & 0.07 \\
\hline SD & 41,387 & 2,862 & 54,664 & 21,356 & 5.50 & 1.35 & 1.24 & 0.09 & 0.05 \\
\hline Min. & 2,410 & 488 & 2,211 & 1,868 & 8.66 & 1.34 & 2.00 & 0.08 & 0.00 \\
\hline Max. & 187,650 & 13,018 & 282,223 & 91,158 & 37.12 & 8.42 & 8.90 & 0.50 & 0.25 \\
\hline \multicolumn{10}{|l|}{2001} \\
\hline Mean & 35,364 & 3,557 & 56,152 & 29,476 & 18.14 & 4.78 & 5.68 & 0.24 & 0.08 \\
\hline SD & 41,995 & 2,736 & 60,546 & 28,967 & 6.90 & 1.57 & 1.45 & 0.09 & 0.06 \\
\hline Min. & 1,972 & 488 & 2,008 & 2,108 & 9.00 & 2.96 & 3.50 & 0.03 & 0.00 \\
\hline Max. & 189,790 & 12,823 & 325,205 & 115,582 & 34.36 & 11.14 & 10.10 & 0.49 & 0.41 \\
\hline \multicolumn{10}{|l|}{2002} \\
\hline Mean & 40,638 & 3,614 & 55,859 & 33,184 & 22.52 & 5.57 & 6.66 & 0.26 & 0.09 \\
\hline SD & 50,177 & 2,806 & 60,154 & 33,200 & 7.69 & 1.46 & 1.45 & 0.09 & 0.08 \\
\hline Min. & 1,440 & 488 & 1,950 & 2,040 & 10.72 & 3.44 & 4.00 & 0.04 & 0.00 \\
\hline Max. & 224,395 & 13,047 & 320,193 & 142,639 & 40.10 & 9.36 & 10.40 & 0.54 & 0.58 \\
\hline \multicolumn{10}{|l|}{2003} \\
\hline Mean & 40,642 & 3,352 & 54,126 & 33,869 & 26.29 & 9.59 & 7.97 & 0.25 & 0.07 \\
\hline SD & 56,276 & 2,624 & 54,754 & 36,131 & 7.96 & 3.60 & 1.26 & 0.08 & 0.05 \\
\hline Min. & 2,067 & 536 & 2,019 & 2,928 & 11.69 & 4.31 & 5.80 & 0.05 & 0.00 \\
\hline Max. & 317,239 & 12,891 & 261,660 & 161,283 & 39.95 & 16.65 & 11.20 & 0.43 & 0.20 \\
\hline
\end{tabular}

Source: Authors' calculations.

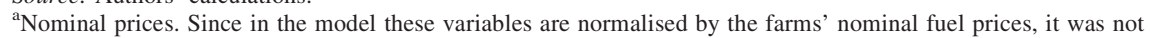
necessary to express them in real terms using deflators.

Table A3. Description of determinants of technical inefficiency and budget constraints

Factor/farms' Variables with significant loadings on the respective factor characteristic

Farm age $\left(q^{\text {age }}\right) \quad$ Period since farm establishment, farm head's years with the farm, average farm managers' years with the farm and dummy for 'new farm head'.

Farm size $\left(q^{\text {size }}\right) \quad$ Farm agricultural area, number of employees, fixed asset value and livestock number.

Managers' ownership Ownership status of the farm head (dummy variable) and share of stake $\left(q^{\text {own }}\right)$

Farm managerial the farm's co-owners in the total number of farm managers. competence $\left(q^{\text {manag }}\right)$

Level of initial Share of managers with higher education. technology $\left(q^{\text {tech99}}\right)$

Technology level in the crop and livestock production, respectively, as evaluated by the farm head for 1999 (with higher scores for more advanced technologies).

Production risk magnitude $\left(q^{\text {risk }}\right)$

Production risk severity as evaluated by the farm head (with higher scores indicating higher risk exposure). 
Table A3. Description of determinants of technical inefficiency and budget constraints (continued)

Factor/farms' Variables with significant loadings on the respective factor characteristic

Farm diversification Degree of diversification within agriculture and reliance on $\left(q^{\text {div }}\right) \quad$ external processing capacities.

The factors used are based on the factor analysis conducted by Bokusheva et al. (2007) for the same data set. The factors follow a standard normal distribution. More details on the factor analysis and descriptive statistics for relevant variables can be found in Bokusheva et al. (2007: 60-62 and 71).

\section{Appendix B}

\section{B.1. The econometric model}

The econometric model consists of the IPF and $(J-1)$ cost share equations. To accommodate panel data, we amend equation (11) by introducing time variable $t$. This results in the following IPF system:

$$
\begin{aligned}
\ln y_{i t}= & \alpha_{0}+\sum_{j=1}^{J-1} \alpha_{j} \ln \tilde{w}_{j i t}+\sum_{m=1}^{M} \alpha_{m} \ln z_{m i t}+\alpha_{C} \ln \tilde{C}_{i t}+\alpha_{t} t+\alpha_{t t} t^{2} \\
& +\sum_{j=1}^{J-1} \alpha_{j t} \ln \tilde{w}_{j i t} t+\sum_{m=1}^{M} \alpha_{m t} \ln z_{m i t} t+\alpha_{C t} \ln \tilde{C}_{i t} t \\
& +\frac{1}{2}\left\{\sum_{k=1}^{J-1} \sum_{j=1}^{J-1} \alpha_{j k} \ln \tilde{w}_{j i t} \ln \tilde{w}_{k i t}+\alpha_{C C}\left(\ln \tilde{C}_{i t}\right)^{2}+\sum_{l=1}^{M} \sum_{m=1}^{M} \alpha_{m l} \ln z_{m i t} \ln z_{l i t}\right\} \\
& +\sum_{m=1}^{M} \sum_{j=1}^{J-1} \alpha_{j m} \ln \tilde{w}_{j i t} z_{m i t}+\sum_{j=1}^{J-1} \alpha_{j C} \ln \tilde{w}_{j i t} \ln \tilde{C}_{i t}+\sum_{m=1}^{M} \alpha_{m C} \ln z_{m i t} \\
& \ln \tilde{C}_{i t}+v_{i t}-u_{i t} \\
S_{j i t}= & -\frac{\varepsilon_{y j i t}}{\varepsilon_{y C i t}}+r_{j i t}, \quad \forall j=1, \ldots, J-1, i=1, \ldots, n, t=1, \ldots, T, \quad \text { (A2) }
\end{aligned}
$$

where

$$
\begin{gathered}
\varepsilon_{y C i t}=\alpha_{C}+\alpha_{C t} t+\alpha_{C C} \ln \tilde{C}_{i t}+\sum_{j=1}^{J-1} \alpha_{j C} \ln \tilde{w}_{j i t}+\sum_{m=1}^{M} \alpha_{m C} \ln z_{m i t}, \\
\varepsilon_{y j i t}=\alpha_{j}+\alpha_{j t} t+\alpha_{j C} \ln \tilde{C}_{i t}+\sum_{j=1}^{J-1} \alpha_{j k} \ln \tilde{w}_{k i t}+\sum_{m=1}^{M} \alpha_{j m} \ln z_{m i t}
\end{gathered}
$$

and $r_{j i t}$ are classical disturbance terms added to the share equations. Note that homogeneity (of degree zero) conditions are imposed by scaling all the input prices and cost by the price of the $j$ th input $\left(w_{J}\right)$, i.e. input prices and cost in the 
IPF and share equations are replaced by the normalised (scaled) prices $\tilde{w}_{j}=w_{j} / w_{J}, j=1, \ldots, J-1$ and normalised cost $\tilde{C}=C / w_{J}$. This scaling procedure imposes the homogeneity restrictions and drops the $J$ th share equation. Thus, the econometric model consists of equations (A1) and (A2), which is a system of $J$ equations.

Since we use a translog function for the IPF, the hypotheses about farms expenditure constraints can be expressed as $H_{0}: \partial \ln y / \partial \ln C=C / y, H_{A}: \partial \ln$ $y / \partial \ln C \neq C / y$. The null hypothesis is non-linear in parameters and it can be expressed as $g(\mathbf{w}, C, z ; \theta)=0$, which can tested (at each point) from $g /(\hat{\boldsymbol{\theta}})[G /(\hat{\boldsymbol{\theta}}) V(\hat{\boldsymbol{\theta}}) G(\hat{\boldsymbol{\theta}})]^{-1} g(\hat{\boldsymbol{\theta}}) \sim \chi^{2}(q)$ where $\hat{\boldsymbol{\theta}}$ is the estimated parameter vector, $\mathrm{V}(\hat{\boldsymbol{\theta}})$ is the estimated variance-covariance matrix of $\hat{\boldsymbol{\theta}}, G(\cdot)=\partial g(\cdot) / \partial \theta$ and $q$ is the number of hypotheses in $g(\cdot)=0$ (see Amemiya, 1985; Gallant, 1987). Since this test is done at every point and we have one restriction, $G(\cdot)$ is a column vector whose dimension equals the number of parameters in $g(\cdot)$.

Corresponding author: Subal C. Kumbhakar, Department of Economics, State University of New York in Binghamton, PO Box 6000, Binghamton, NY 13902-6000, USA. Email: kkar@binghamton.edu 